\title{
Impact of Enzymatic Degradation on the Material Properties of Poly(Ethylene Terephthalate)
}

\author{
Teresa Menzel ${ }^{1, \dagger}{ }^{\text {, Sebastian Weigert }}{ }^{2,+}{ }^{\oplus}$, Andreas Gagsteiger ${ }^{2}\left(\mathbb{D}\right.$, Yannik Eich ${ }^{1}$, Sebastian Sittl ${ }^{3}$, \\ Georg Papastavrou ${ }^{3}$, Holger Ruckdäschel ${ }^{1}$, Volker Altstädt ${ }^{1}[1]$ and Birte Höcker ${ }^{2, *}$ (i) \\ 1 Department of Polymer Engineering, University of Bayreuth, Universitätsstraße 30, \\ 95447 Bayreuth, Germany; Teresa.Menzel@uni-bayreuth.de (T.M.); bt716629@uni-bayreuth.de (Y.E.); \\ holger.ruckdaeschel@uni-bayreuth.de (H.R.); volker.altstaedt@uni-bayreuth.de (V.A.) \\ 2 Department of Biochemistry, University of Bayreuth, Universitätsstraße 30, 95447 Bayreuth, Germany; \\ Sebastian.Weigert@uni-bayreuth.de (S.W.); Andreas.Gagsteiger@uni-bayreuth.de (A.G.) \\ 3 Department of Physical Chemistry II, University of Bayreuth, Universitätstraße 30, 95447 Bayreuth, Germany; \\ sebastian.sittl@uni-bayreuth.de (S.S.); Georg.Papastavrou@uni-bayreuth.de (G.P.) \\ * Correspondence: birte.hoecker@uni-bayreuth.de \\ + These authors contributed equally to this work.
}

check for updates

Citation: Menzel, T.; Weigert, S.; Gagsteiger, A.; Eich, Y.; Sittl, S.;

Papastavrou, G.; Ruckdäschel, H.;

Altstädt, V.; Höcker, B. Impact of Enzymatic Degradation on the Material Properties of Poly(Ethylene Terephthalate). Polymers 2021, 13, 3885. https://doi.org/10.3390/ polym 13223885

Academic Editor: Andrea Sorrentino

Received: 23 September 2021

Accepted: 8 November 2021

Published: 10 November 2021

Publisher's Note: MDPI stays neutral with regard to jurisdictional claims in published maps and institutional affiliations.

Copyright: (C) 2021 by the authors Licensee MDPI, Basel, Switzerland. This article is an open access article distributed under the terms and conditions of the Creative Commons Attribution (CC BY) license (https:// creativecommons.org/licenses/by/ $4.0 /)$.
Abstract: With macroscopic litter and its degradation into secondary microplastic as a major source of environmental pollution, one key challenge is understanding the pathways from macro- to microplastic by abiotic and biotic environmental impact. So far, little is known about the impact of biota on material properties. This study focuses on recycled, bottle-grade poly(ethylene terephthalate) (r-PET) and the degrading enzyme PETase from Ideonella sakaiensis. Compact tension (CT) specimens were incubated in an enzymatic solution and thermally and mechanically characterized. A timedependent study up to $96 \mathrm{~h}$ revealed the formation of steadily growing colloidal structures. After $96 \mathrm{~h}$ incubation, high amounts of BHET dimer were found in a near-surface layer, affecting crack propagation and leading to faster material failure. The results of this pilot study show that enzymatic activity accelerates embrittlement and favors fragmentation. We conclude that PET-degrading enzymes must be viewed as a potentially relevant acceleration factor in macroplastic degradation.

Keywords: polymer degradation; microplastic; nanoplastic; PETase; crack formation; fatigue crack propagation resistance; BHET; enzymatic degradation; enzyme; Ideonella sakaiensis; bis(hydroxyethyl)terephthalate

\section{Introduction}

Since the discovery of microplastics (MPs) in 2004 [1], particles have been detected in almost every natural environment. Primary MP is already produced on a micrometer scale, whereas secondary MP arises by degradation and fragmentation of macroplastic. As the amount of secondary MP to be found in nature is drastically larger than that of primary MP, the degradation of macroplastic has recently gained new attention [2-4]. Once in the environment, polymers are exposed to a range of external environmental impacts. These can be categorized as abiotic factors such as UV-radiation, temperature, humidity, and mechanical stress, and biotic factors such as living or dead organisms, e.g., biofilm formation by bacteria, fungi, algae, or ingestion [5,6]. A complex interplay of natural stress factors is supposed to lead to molecular degradation, fragmentation, and therefore MP formation [7-9]. However, knowledge of the underlying processes is still lacking. It is evident that material properties decisively influence the fragmentation towards MP and dramatically change during this process, creating a feedback loop on the degradation itself.

Regarding biotic degradation, polyesters, especially polyethylene terephthalate (PET), are the subject of many studies due to their molecular structure [10]. Ester bonds are omnipresent in key positions within metabolic networks and biological molecules. Although other common polymer bond types like $\mathrm{C}-\mathrm{C}$ are more challenging in a biological 
perspective, a whole variety of hydrolases is known to deal with ester bonds in nature. Particularly in recent years, PET-degrading enzymes have come into focus as a new perspective for biological MP decomposition and recycling applications [11]. In this regard, cutinase enzymes are of particular interest, as their aliphatic ester substrate, cutin, has a chemical resemblance to PET. Consequently, all PET-degrading enzymes with relevant activity known to date can be assigned to this group of cutinases [10], including the beststudied variants TfCut-1/2 (Thermobifida fusca) [11], LCC (uncultured organism) [12], and PETase (Ideonella sakaiensis) [13]. The latter piqued researchers' interest, as it appeared as the first evolved PET-degrading enzyme with substantial activity at ambient temperatures. This activity profile, combined with the presence of potential PET-degrading enzymes in different ecosystems [14], suggests the altering of PET's material properties upon biological activity under real conditions.

On a chemical level, abiotic factors are relatively well characterized: Photooxidation by UV radiation and oxygen leads to radical-induced chain scission and the formation of new polar functional end groups, e.g., carboxylic acids, aldehydes, hydroxides, or peroxides [15-18]. Hydrolytic degradation strongly depends on an interplay of humidity, temperature, $\mathrm{pH}$, and the crystallinity of the material [17,19-21]. Both processes lead to a decrease in the molecular weight. Regarding material properties, it is well known that the transition of the molecular weight below the critical molar mass $\left(\mathrm{M}_{\mathrm{c}}, 17 \mathrm{~kg} / \mathrm{mol}\right.$ for PET [22]) causes a change in material behavior from ductile to brittle [23]. In general, abiotic degradation and stepwise embrittlement accelerate the fragmentation upon external mechanical forces like wind and waves [24,25]. However, except for one study [22], there is a lack of detailed information about changes in mechanical properties on PET depending on environmental impact in the literature. When it comes to biotic degradation of PET and its impact on the material, even less is known besides the investigation of changes in PET crystallinity during enzymatic degradation [26].

A sensitive method for the determination of micromechanical material changes can be supplied by mechanical testing under dynamic load $[27,28]$. This technique gives precise information on the fatigue crack propagation (FCP) behavior at various crack propagation speeds and is claimed to be the most sensitive regarding the relationships between the polymer structure and deformation mechanism. The stress state at the crack tip is well defined compared to conventional tensile or impact testing. This allows possible correlations between the interaction of the crack tip, propagation of the fatigue crack, and the sensitivity of a specific polymer to environmental stress. It is well known that the FCP rate is strongly affected by the degree of crystallinity and the tie molecule density of polymers [29,30], as well as by their molecular weight [31]. Eventually, the linear dependency of the FCP rate on the applied stress intensity, indicating stable crack growth, provides qualitative information about improved or deteriorated material behavior [32].

To the best of our knowledge, there have been no studies focusing on the impact of biotic stresses on macroscopic PET properties. For detailed information on the formation of MP on their pathway from macro to micro, biotic factors on material properties must be considered. Within this feasibility study, we combine the methods and techniques of biochemistry and engineering sciences. This interdisciplinary combination allows first insights into the change of material properties in a laboratory-controlled biotic degradation process. Overall, the aim of our study is to understand the impact of biotic degradation by PETase on a macro- and microscopic level by focusing on PET material properties. Insights into the underlying processes enable us to comprehend how biotic degradation impacts PET fragmentation.

\section{Materials and Methods}

A commercially available, recycled, low-molecular-weight PET (CleanPET ${ }^{\circledR}$ FK) (Veolia Deutschland $\mathrm{GmbH}$, Berlin, Germany) was used with a number-averaged molecular weight of $\mathrm{M}_{\mathrm{n}}=30.155 \mathrm{~g} / \mathrm{mol}$ and dispersity $=1.8$ determined by GPC measurements (Agilent 1200 Series, Agilent Technologies, Waldbronn, Germany) with HFIP with potas- 
sium trifluoroacetate (4.8 $\mathrm{g}$ in $600 \mathrm{~mL}$ HFIP) as solvent. The PET flakes were acquired from disposable, post-consumer bottles and therefore contained an undeterminable amount of several additives. Thus, the material composition reflected a realistic condition regarding real-life environmental conditions.

\subsection{Protein Production and Purification}

The gene of isPETase was cloned via Gibson assembly [33] in a pMAL-p4x vector, in which the MPB sequence was replaced with the mauC signal peptide for periplasmic expression. E. coli BL21 cells containing the plasmid were grown in TB media at $37^{\circ} \mathrm{C}$; after an OD600 of 1.5 was reached the temperature was lowered to $18{ }^{\circ} \mathrm{C}$ and protein expression was induced with a final concentration of $300 \mu \mathrm{M}$ IPTG. After $18 \mathrm{~h}$, cells were harvested and resuspended for sonication in lysis buffer $(300 \mathrm{mM} \mathrm{NaCl}, 40 \mathrm{mM}$ imidazole, $50 \mathrm{mM}$ phosphate $\mathrm{pH}$ 7.4). The lysate was clarified through centrifugation $(50,000 \times g)$ and vacuum filtration $(0.2 \mu \mathrm{m}$ filter), and subsequently loaded onto a NiIMAC column (HisTrap FF $5 \mathrm{~mL}$, Cytiva Europe, Freiburg, Germany). After loading and washing, the protein was recovered from the column with elution buffer $(300 \mathrm{mM} \mathrm{NaCl}, 400 \mathrm{mM}$ imidazole, $50 \mathrm{mM}$ phosphate $\mathrm{pH}$ 7.4). For final polishing, the protein was applied to a SEC column (Superdex 75pg 26/60, Cytiva) equilibrated with SEC buffer (150 mM NaCl, 25 mM HEPES, pH 7.4). A total of $100 \mu \mathrm{L}$ aliquots of the enzyme with a concentration of $25 \mu \mathrm{M}$ were flash frozen and kept at $-80^{\circ} \mathrm{C}$ until further use.

\subsection{PET Sample Preparation}

Compact tension (CT) specimens with a width and thickness of 40 and $4 \mathrm{~mm}$, respectively, were prepared by injection molding (Arburg Allrounder 470H 1000-170, Arburg $\mathrm{GmbH}$, Loßburg, Germany). Each sample was tapped with a new razor blade into the V-notch to create a sharp crack. For a time-dependent degradation study of the surfaces, squares with $2 \mathrm{~cm}$ edge length were sawn out of the injection-molded CT specimen for easier handling.

\subsection{Sample Incubation with PETase}

For the time-dependent degradation study, the squares with $2 \mathrm{~cm}$ edge length were fully covered with an enzyme-buffer solution in a $50 \mathrm{~mL}$ centrifuge tube. The enzyme concentration was constantly set to $200 \mathrm{nM}$ in a reaction buffer of $50 \mathrm{nM} \mathrm{NaCl}$ and $50 \mathrm{mM}$ borate at $\mathrm{pH}$ 8.5. A control sample was covered under the absence of enzyme with a buffer solution only. All samples were incubated at $30^{\circ} \mathrm{C}$ for $24 \mathrm{~h}, 48 \mathrm{~h}$, and $96 \mathrm{~h}$, respectively. The sample without enzyme is further referred to as control. The PET samples, additionally incubated with enzyme, are further referred to as PET*24 h, PET*48 h, and PET*96 h.

For mechanical testing, the CT specimens were placed in purpose-built holders made of stainless steel (Figure 1). This setup ensured the sufficient coverage of solution at the notch and along the expected crack propagation. The sample holder was assembled with a specimen and filled with $2 \mathrm{~mL}$ of the abovementioned enzyme-buffer solution. Again, a specimen incubated with buffer solution only serves as control sample. The sample holders were placed in a gastight container comprising additional reaction buffer on the bottom to minimize evaporation of the solution within the sample holder. The specimens for mechanical testing were incubated at $30^{\circ} \mathrm{C}$ for $96 \mathrm{~h}$. After exposure, the $\mathrm{CT}$ specimen was rinsed with water and a standard PET drying procedure $\left(6 \mathrm{~h}\right.$ at $\left.140{ }^{\circ} \mathrm{C}\right)$ was applied to eliminate the influence of moisture in further characterization steps. 


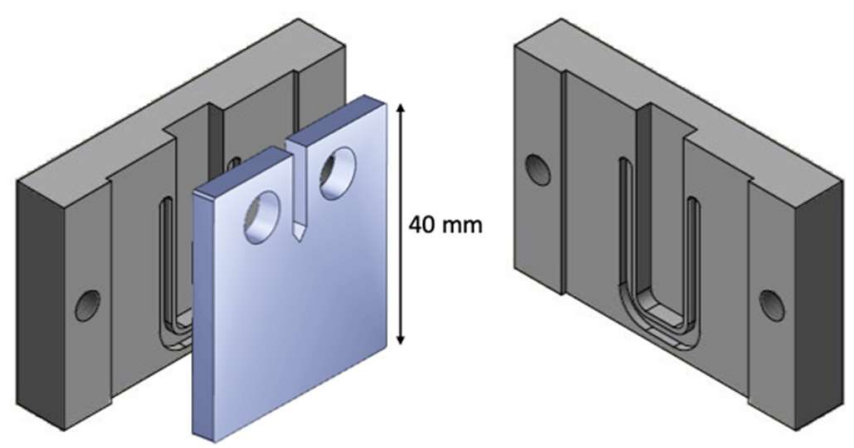

Figure 1. CT specimen and sample holders for the incubation with enzyme-buffer solution. The CT specimen is placed between two perfectly fitting parts, and tightly secured with screws. The indentations are filled either with buffer or enzyme-buffer solution. To avoid leakage of the solutions, U-shaped seals are fixed between specimen and sample holder. The setup ensures the total coverage of the specimen with solution within the expected crack propagation direction.

For this study, incubation parameters such as buffer composition, temperature, and enzyme concentration were chosen primarily to optimize enzymatic activity. Although they did not necessarily reflect conditions in natural settings, they allowed for the best results to establish the methodology.

\subsection{Ultra-High Performance Liquid Chromatography (UHPLC)}

The water-soluble degradation products of PET were quantified with a Thermofisher RS3000 UHPLC system equipped with a Phenomenx Kinetex $1.7 \mu$ m EVO C18 (100 A, $50 \mathrm{~mm} \times 2.1 \mathrm{~mm}$ ) reversed-phase column. For sample preparation, one part of the sample buffer solution of the PET control, PET 24 h, PET*4 4 , and PET* $96 \mathrm{~h}$ after incubation was mixed with four parts acidic acetonitrile ( $1 \%$ formic acid) and centrifuged at $21,000 \times g$ for $10 \mathrm{~min}$. A quantity of $1 \mu \mathrm{L}$ of the supernatant was applied to the column running a gradient from $100 \%$ solvent $\mathrm{A}$ (water $+0.1 \%$ trifluoroacetic acid) to $20 \%$ solvent $\mathrm{A}$ and $80 \%$ solvent $\mathrm{B}$ (acetonitrile) at a flow rate of $1.3 \mathrm{~mL} / \mathrm{min}$ and the column was heated to $55^{\circ} \mathrm{C}$. The product amounts for TPA, MHET, and BHET were quantified based on calibration runs. For the time-dependent monitoring of the enzymatic activity, the three degradation products were summed up to the total product concentration for better comparison.

\subsection{Optical and Topographical Characterization}

To visualize the enzymatic degradation on a microscopic scale, field-emission scanning electron microscopy (FESEM) was performed on the surfaces with a Zeiss Ultra plus (Carl Zeiss Microscopy Deutschland GmbH, Oberkochen, Germany) at an acceleration voltage of $3 \mathrm{kV}$ for the control and the enzyme-degraded samples. All samples were sputtered with $1.3 \mathrm{~nm}$ platin at a Cressington Platin-Sputter Coater 208HR (TESCAN GmbH, Dortmund, Germany) and additionally steamed with $20 \mathrm{~nm}$ carbon at a Leica EM ACE 600 (Leica Microsystems $\mathrm{GmbH}$, Wetzlar, Germany).

The surface topography of the enzymatically degraded PET*96 h and control PET sample was acquired by atomic force microscopy (AFM) imaging in PeakForce tapping mode in air. All images were acquired using a Dimension Icon AFM (Bruker Corporation Billerica, Massachusetts, USA) equipped with a NanoScope V controller. For imaging, ScanAsyst Air cantilevers (Bruker Nano Inc., nominal spring constant $0.4 \mathrm{~N} / \mathrm{m}$, nominal resonance frequency $70 \mathrm{kHz}$ ) were used. The PeakForce frequency was set to $2 \mathrm{kHz}$ with an amplitude of $150 \mathrm{~nm}$. The AFM images were processed with NanoScope Analysis software (version 1.80, Bruker Nano Inc.). In an additional set of experiments, the samples, i.e., enzyme-degraded and control sample surfaces, were treated for about $30 \mathrm{~s}$ by a $\mathrm{CO}_{2}$ gun (SnowJet, Tectra GmbH, Frankfurt, Germany) in order to remove potential organic contaminants. 


\subsection{Thermal Characterization}

Differential scanning calorimetry (DSC) was examined with a Mettler Toledo DSC I (Mettler-Toldeo $\mathrm{GmbH}$, Gießen, Germany) with 8-10 mg sample material. Material was collected between 0 and $1 \mathrm{~mm}$ depth from the surface. The samples were heated under an $\mathrm{N}_{2}$ atmosphere from $-10{ }^{\circ} \mathrm{C}$ to $300^{\circ} \mathrm{C}$ (1st heating run), and cooled to $-10{ }^{\circ} \mathrm{C}$ again after an isothermal stage of $5 \mathrm{~min}$ at $300^{\circ} \mathrm{C}$. For determination of the degree of crystallinity $\mathrm{x}_{\mathrm{c}} \mathrm{a}$ fusion enthalpy of $\Delta \mathrm{Hm}^{\circ}=140.1 \mathrm{~J} / \mathrm{g}$ for a hypothetically $100 \%$ crystalline PET was used, based on the literature [34].

\subsection{Mechanical Characterization}

The FCP behavior was determined according to test method ISO 15850/ASTM E647 at $23{ }^{\circ} \mathrm{C}$ and a relative humidity of $50 \%$ on a servo-hydraulic testing machine (IST IPLH10I, Schenck, Germany) applying a dynamical load with a frequency of $10 \mathrm{~Hz}$ to the samples. The stress intensity factor's $\Delta \mathrm{K}=\mathrm{K}_{\max }-\mathrm{K}_{\min }$ amplitude was increased in proportion to the crack length with a constant $\mathrm{R}=\mathrm{K}_{\min } / \mathrm{K}_{\max }$ of 0.1 . The crack was supposed to grow perpendicular to the load within the solution covered area until the end of the sample. For measurement of the crack opening displacement during crack growth, a clip-on extensometer (632.29-30, MTS Sensor Technology GmbH \& Co. KG, Rottenburg am Neckar, Germany) was used. Each experiment loaded under tension mode was repeated at least three times. Analysis was done with the software R [35]; Zone II was defined manually between $\Delta K=2.2$ and $\Delta K=3.05$.

\section{Results and Discussion}

\subsection{Analysis of Soluble Products}

To monitor enzymatic degradation on the molecular level, the control buffer solution and enzyme buffer solution were analyzed by ultra-high-performance liquid chromatography (UHPLC) after the given incubation time of $24 \mathrm{~h}, 48 \mathrm{~h}$, and $96 \mathrm{~h}$. Regarding product composition, the exemplarily plotted buffer solution of PET*96 h contained the typical degradation products terephthalic acid (TPA), mono-(2-hydroxyethyl)terephthalic acid (MHET), and bis(hydroxyethyl)terephthalate (BHET) (Figure 2a). In the case of the control buffer, none of the typical degradation products could be detected (Figure 2a). The quantification of the degradation products for PET ${ }^{*} 96 \mathrm{~h}$ (Figure $2 \mathrm{~b}$ ) gave high amounts of MHET and TPA with $2.3 \mathrm{mM}$ and $1.3 \mathrm{mM}$, respectively. Further, small amounts of $0.1 \mathrm{mM}$ BHET were identified. For the time-dependent study, the total product concentration for $\mathrm{PET}^{*} 24 \mathrm{~h}, \mathrm{PET}^{*} 48 \mathrm{~h}$, and $\mathrm{PET}^{*} 96 \mathrm{~h}$ was determined. The total product concentration increased in relation to the incubation time, with a slight slowdown after $48 \mathrm{~h}$ (Figure 2c). The results of the solution analysis represent a typical activity profile for PETase on PET with MHET as the dominant product [13].

The UHPLC measurements verify that the observed PET degradation could only be attributed to enzymatic activity and no side reaction or autohydrolysis occurred during incubation. Furthermore, the results reflect the consistency in our setup, including sample generation and incubation. True to expectations [36], the total product release, consisting of TPA, MHET, and BHET, steadily rose with increasing exposure time (Figure 2c). This indicates a constantly ongoing degradation of PET by PETase over incubation time. In summary, the setup ensured a reliable procedure for monitoring enzymatic activity of a macroscopic substrate on the molecular level. 
a)

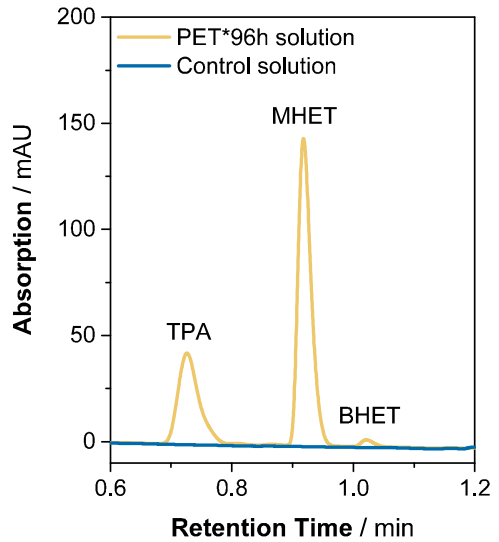

b)

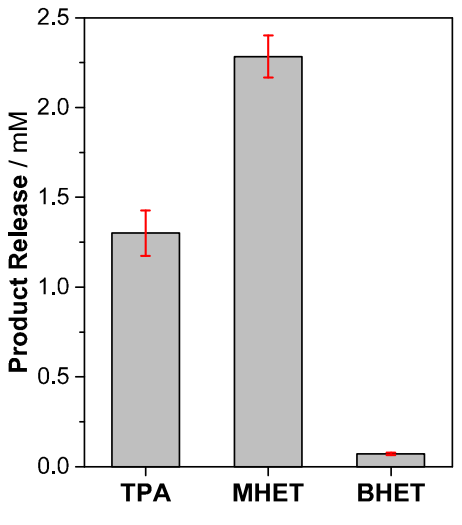

c)



Figure 2. Analysis of soluble products. (a) UHPLC results of the control buffer solution (blue) and enzyme buffer solution (orange) of PET ${ }^{*} 96 \mathrm{~h}$. For the control buffer solution, no release products could be detected. (b) Product concentrations of $\mathrm{PET}^{*} 96 \mathrm{~h}$ to display the product composition in $\mathrm{mM}$ and (c) total product concentration of $\mathrm{PET}^{*} 24 \mathrm{~h}, \mathrm{PET}^{*} 48 \mathrm{~h}$, and PET $^{*} 96 \mathrm{~h}$ solution versus incubation time.

\subsection{Characterization of PET Material Properties}

To investigate the result of degradation on a visible level, scanning electron microscopy (SEM) micrographs of the surfaces of the control and incubated PET samples were recorded (Figure 3).
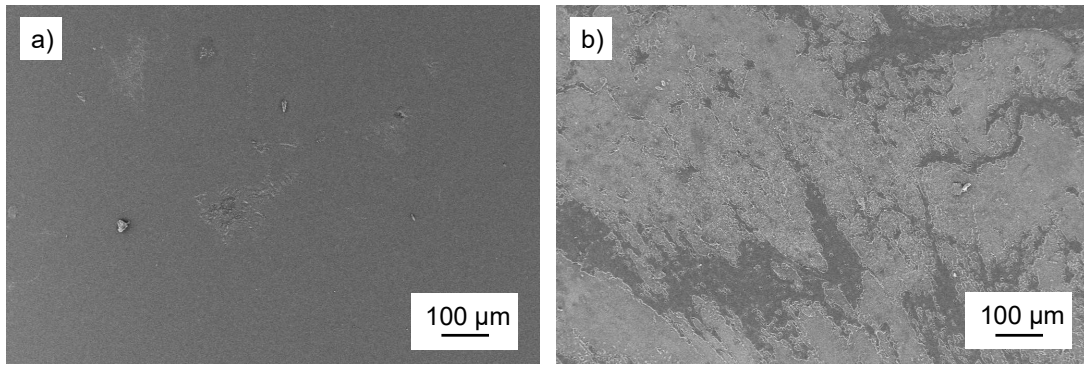

Figure 3. SEM micrographs for comparison of the (a) control PET surface and (b) PET surface of $\mathrm{PET}^{*} 96 \mathrm{~h}$ after incubation.

In the case of the control PET, the micrographs displayed a smooth and unaffected surface (Figure 3a). The exposure of the samples to PETase enzyme led to visible degradation by surface erosion (Figure 3b), indicating successful trials and degradation. The overview at low magnification depicted the spatial heterogeneity of the enzymatic treatment, reflected by the presence of unaffected and degraded areas. Furthermore, the investigation of the control sample surface verified that it was not affected by autohydrolysis of the buffer solution and degradation only arose due to the impact of enzymes. For a deeper investigation of the topographical surfaces' changes, a time-dependent surface SEM study was performed.

The SEM micrographs of the time-dependent degradation study are shown in Figure 4. The affected areas at higher magnitudes showed the presence of colloidal structures upon enzymatic treatment. They constantly grew with increasing incubation time to a diameter of approx. $2 \mu \mathrm{m}$. However, at that point we could not distinguish between surface erosion and the congregation of side products on the PET surface during the enzymatic degradation. 

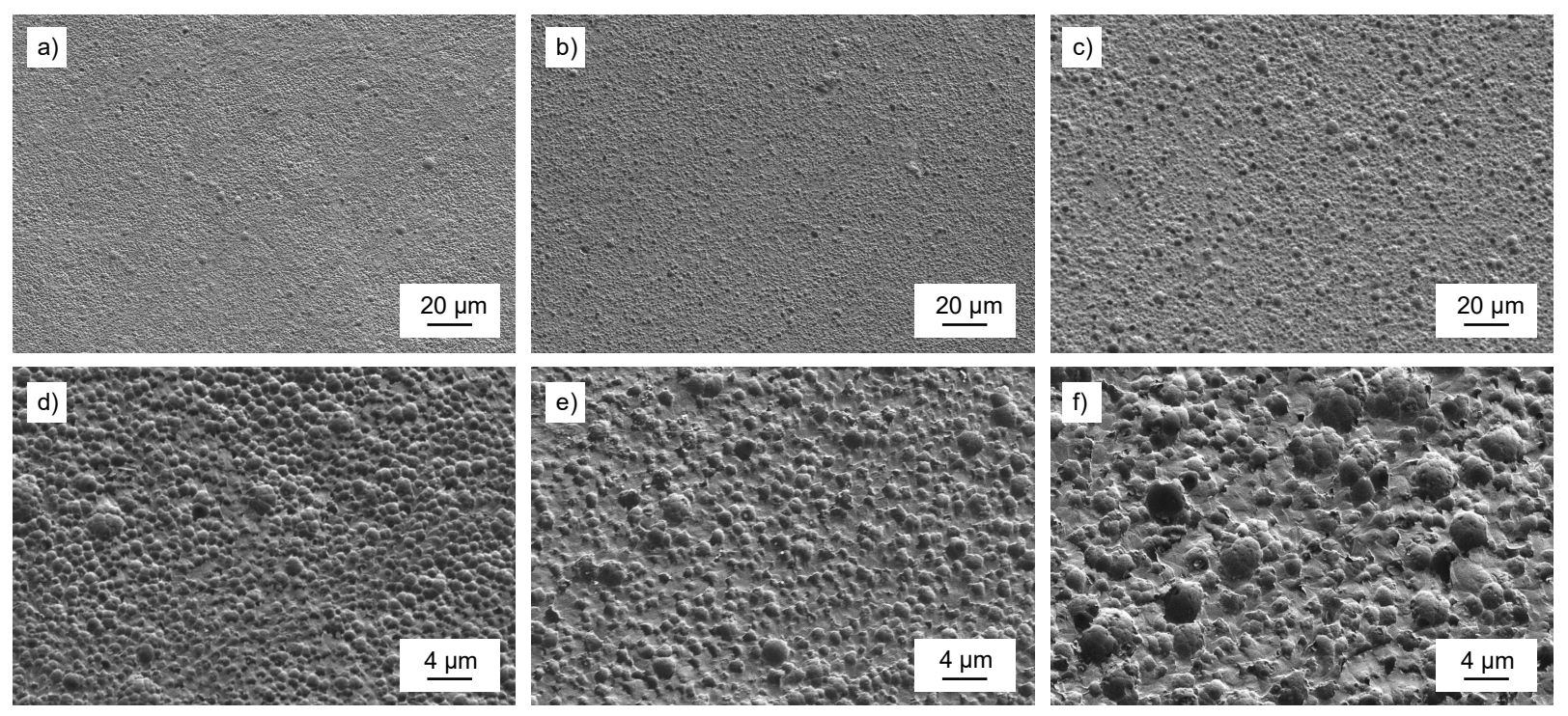

Figure 4. Time-dependent SEM micrographs at different degradation stages of (a) PET*24 h, (b) PET*48 h, and (c) PET*96 h and with higher magnification at (d) $\mathrm{PET}^{*} 24 \mathrm{~h},(\mathbf{e}) \mathrm{PET}^{*} 48 \mathrm{~h}$, and (f) $\mathrm{PET}^{*} 96 \mathrm{~h}$.

To corroborate the topography changes upon enzymatic treatment as determined by SEM, we studied the PET surface of the control and enzyme-treated PET*96 h sample additionally by AFM. For those measurements we used PeakForce Tapping mode (Figure 5) as the imaging mode to correlate the colloidal growth with surface roughness.

a)

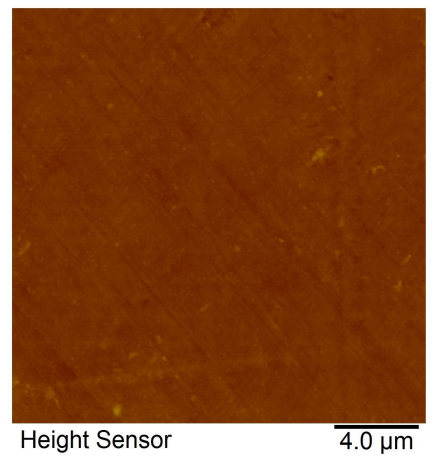

b)

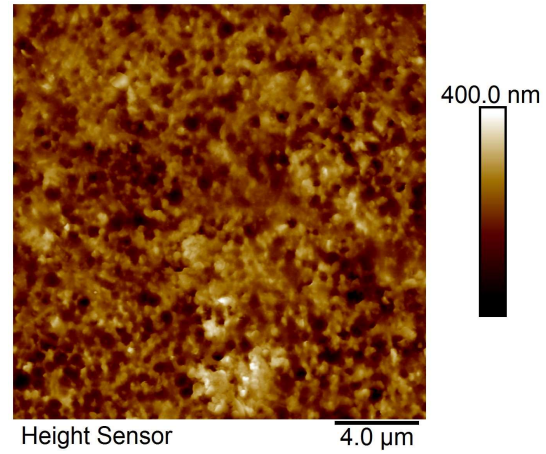

Figure 5. PeakForce Tapping mode AFM images of the control PET surface (a) and PET*96 h surface (b).

The blank PET surface was smooth (Figure 5a). The sample showed a homogeneous surface without any distinct topographical features. On the other hand, the PET*96 h surface, which was incubated and treated with the PETase, showed a significant increase in roughness. Figure $5 b$ bears distinct differences in surface topography with features that are absent for the bare control PET substrate (cf. Figure 5a). The observed increase in surface roughness is in line with the findings from the SEM investigations (cf. Figure 4) and indicates that the enzymatic treatment was accompanied by changes in the surface topography. In order to further quantify this finding, the arithmetic surface roughness was evaluated for at least three AFM images for each type of PET sample. The untreated surface bore a roughness of $7.3 \mathrm{~nm} \pm 3.7 \mathrm{~nm}$ and the PETase-treated samples bore a roughness of $37.0 \mathrm{~nm} \pm 7.8 \mathrm{~nm}$, respectively.

Differential scanning calorimetry (DSC) measurements allow inferences to be drawn from thermal transition temperatures about molecular arrangements. Until now, the focus in literature dealing with enzymatic degradation has been the identification of degradation products in solution $[13,26,37]$, but no concrete measurements have been carried out on 
PET sample surfaces. DSC thermograms of the heating curves and cooling curves for the PET control and PET ${ }^{*} 96 \mathrm{~h}$ sample are shown in Figure 6. The DSC samples were taken along the crack of a CT specimen at a $0-1 \mathrm{~mm}$ sample depth.

a)


Figure 6. DSC thermograms of the first heating run (a) and first cooling run (b) for PET blank (blue) and PET incubated with PETase (orange). For the enzyme-treated samples, the rise of a second melting peak was identified as BHET dimer.

In the first heating curve (Figure 6a), both samples showed the PET typical melting point $\mathrm{T}_{\mathrm{m}}=250{ }^{\circ} \mathrm{C}$ [38]. Beside the glass transition $\mathrm{T}_{\mathrm{g}, \mathrm{b}}=76^{\circ} \mathrm{C}$, the control sample additionally showed an exothermic peak at $\mathrm{T}_{\text {cryst, }}=120^{\circ} \mathrm{C}$ related to amorphous phase crystallization. In the case of the incubated $\mathrm{PET}^{*} 96 \mathrm{~h}$ sample, the glass transition showed a weak signal at $\mathrm{T}_{\mathrm{g}, \mathrm{e}}=84^{\circ} \mathrm{C}$. The increase in the glass transition temperature of incubated PET can be explained by the emergence of crystalline units of two different molecular species in a range from 109 to $172{ }^{\circ} \mathrm{C}$ (Figure 6a). They were supposed to immobilize the amorphous chains [39], which led to the slight increase of $8 \mathrm{~K}$.

The appearance of these new melting peaks can be attributed in detail to PET oligomers with a varying length of one and two monomer repeating units, respectively [40]. Whereas the weaker signal from $109^{\circ} \mathrm{C}$ to $135^{\circ} \mathrm{C}$ could be attributed to monomeric BHET, the melting point at $\mathrm{T}_{\mathrm{m} \text {,dimer }}=164^{\circ} \mathrm{C}$ clearly indicates the presence of BHET dimer [41-43]. The observed BHET dimer was water-insoluble and therefore not detectable in UHPLC measurements of the solutions. We conclude that the observed colloidal structures (Figure 4) on the surface were composed of BHET oligomer species. However, the accumulation of BHET and its dimer indicates that they were not preferably degraded by the PETase.

A possible explanation for this behavior lies in the topology of the enzyme itself. Although there is no experimental proof for the exact binding mode of PET substrate to PETase, it is known that the PET binding site includes an L-shaped shallow grove neighboring the active site. Several studies using computational calculations to dock a PET oligomer in the active and binding site yielded a binding pose that provides space for the equivalent of either a BHET trimer or tetramer [26,44,45]. Shorter substrates such as the BHET dimer are not able to cover the full binding site, leading to a potentially decreased number of atomic contacts that contribute to the binding of the substrate. This would result in a higher affinity for higher oligomers in enzymatic catalysis followed by an accumulation of BHET dimer. Consequently, enzymatic activity might be underestimated when only soluble products are tracked.

The degree of crystallinity decreased with enzymatic treatment from $x_{c, b}=22 \%$ for the PET control to $x_{c, e}=18 \%$ for the PET ${ }^{*} 96 \mathrm{~h}$ sample. It is known that high crystallinity impairs enzymatic activity, which led to the conclusion that PETase was mainly active in the amorphous regions. If this was the case, crystallinity should have increased. However, our results show that the degree of PET crystallinity decreased after enzymatic incubation, 
as reported in previous studies [22]. We assume that this lower degree in crystallinity of PET was not directly caused by enzymatic attack on crystalline regions, but rather by BHET species disrupting the crystalline order on the surface, explaining how crystallinity can decrease despite preferred enzymatic degradation of amorphous regions. The presence of BHET was also observed in the cooling curves (Figure $6 \mathrm{~b}$ ). Whereas the control sample only showed one sharp recrystallization peak at $\mathrm{T}_{\mathrm{c}, \mathrm{PET}}=200^{\circ} \mathrm{C}$ typical for PET, the PET ${ }^{*} 96 \mathrm{~h}$ cooling curve showed an additional peak at $\mathrm{T}_{\mathrm{c} \text {,dimer }}=117^{\circ} \mathrm{C}$, corresponding to BHET dimer recrystallization. The earlier onset of PET incubated with PETase recrystallization could be a nucleation effect induced by the additional oligomeric fraction.

To further investigate the impact of enzymatic degradation on the surface and therefore on the material's properties, dynamic mechanical measurement over a whole range of stress intensities was performed. In Figure 7, the fatigue growth rate, da/dN, for six averaged curves of PET*96 $\mathrm{h}$ and PET control sample versus the applied stress intensity factor $\Delta \mathrm{K}$ at the crack tip was plotted to investigate the FCP behavior.



Figure 7. FCP behavior of the PET control (light blue, blue, dark blue) and PET*96 h (yellow, orange, brown) samples in a double logarithmic scale with the division into three relevant regions, marked by the dashed lines and grey color.

In general, $\mathrm{da} / \mathrm{dN}$ curves can be subdivided into three different crack propagation regions, as shown in Figure 7. Region I describes the crack propagation after reaching the threshold value $\Delta \mathrm{K}_{\text {th }}$. Below this value, crack propagation is negligibly low. Region II represents stable crack growth according to the Paris-Erdogan Equation da $/ \mathrm{dN}=\mathrm{C}(\Delta \mathrm{K})^{\mathrm{m}}$, where $C$ and $m$ are material constants. Region III is determined by instable crack propagation until the final fracture of the sample.

In the case of PET, the behavior of the material did not significantly differ from the control sample in region I, except for one enzyme-incubated sample with a lower threshold value. This can be explained by the inhomogeneities of biotic treatment, as observed in SEM (Figure 3). However, with increasing mechanical load upon region II, the empowered crack propagation rates of the PET $* 6 \mathrm{~h}$ samples indicate the reduction in crack growth resistance. These results are consistent with the formation of BHET species on the surface, which is associated with the breakdown of individual polymer chains and material deterioration. The degradation of individual polymer chains results in a decreasing number of links between the crystalline PET units, so-called tie-molecules. With decreasing tiemolecule density, the craze network is destabilized, and the induced dynamic load causes 
molecular fracture, resulting in macroscopically brittle behavior [46,47]. Additionally, the development of a craze network could be interrupted by those additional crystalline units of BHET oligomers. Consequently, complete failure of the enzyme-treated material can be investigated at lower stress intensities compared to the control samples in region III accompanied by a faster crack growth velocity.

To quantify the influence of enzymatic degradation, a fit was applied to each measurement in the linear-dependent stable crack propagation in region II (Figure 8). The linear fit in a logarithmic scale shows the impact of enzymes in combination with mechanical stress. Without enzymatic treatment, an average slope of $\mathrm{m}_{\mathrm{b}}=5.5 \pm 1.1$ can be calculated according to $\mathrm{y}=\mathrm{a} \times \mathrm{x}^{\mathrm{m}}$ for the PET control. In comparison to the PET ${ }^{*} 66 \mathrm{~h}$ sample, the value of the slope increased to $m_{e}=10.2 \pm 1.4$. This clearly identifies an impact of PETase on the degradation behavior on the path from macro- to microplastic by fragmentation due to mechanical stress.

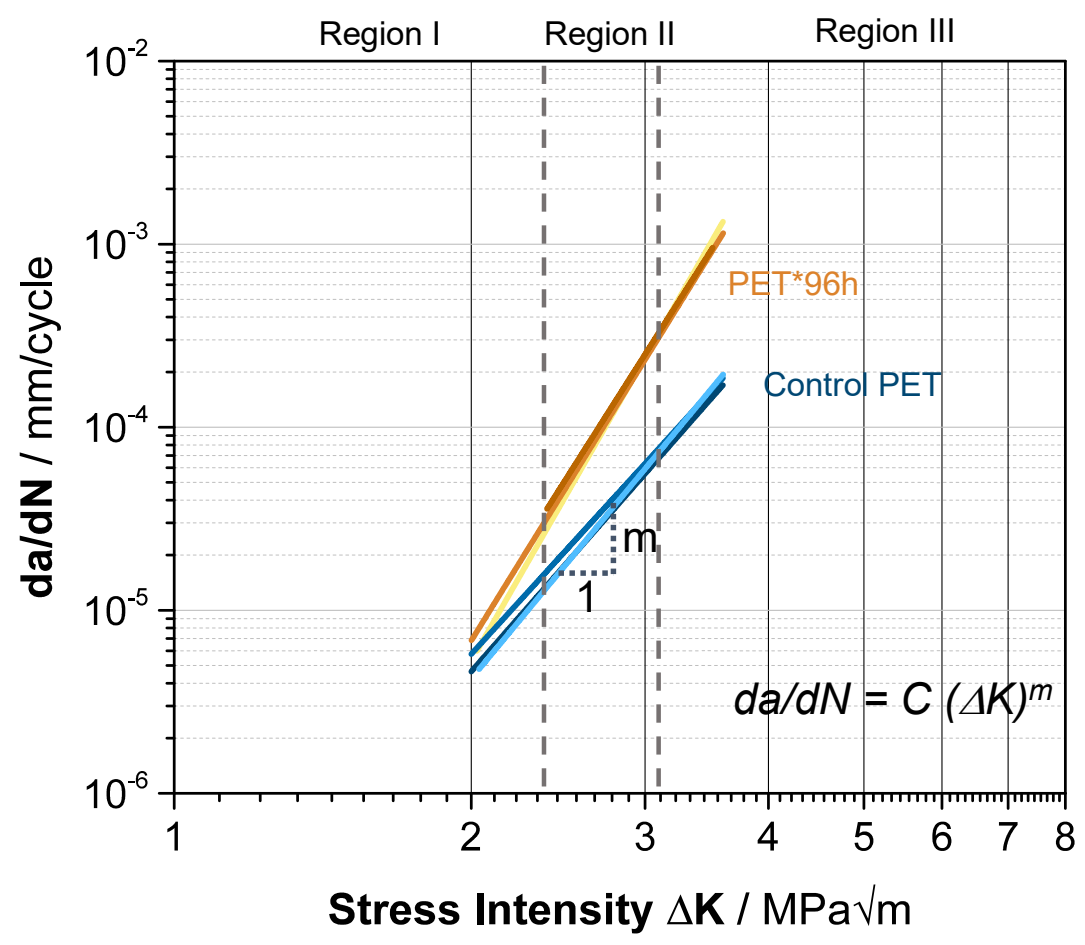

Figure 8. Power function fit of the FCP data on the linear range in region II in a double logarithmic scale with curves for the PET control (light blue, blue, dark blue) and PET ${ }^{*} 96 \mathrm{~h}$ (yellow, orange, dark orange). The averaged parameters for the fit are $\mathrm{m}_{\mathrm{b}}=5.5 \pm 1.1, \mathrm{C}_{\mathrm{b}}=10-7.9 \pm 0.5$ for the PET control samples, and $\mathrm{m}_{\mathrm{e}}=10.2 \pm 1.4, \mathrm{C}_{\mathrm{e}}=10-8.4 \pm 0.6$ for PET $* 96 \mathrm{~h}$.

\section{Conclusions}

The time-dependent investigation of PET samples exposed to PETase showed the formation of colloidal structures growing with incubation time and thereby increasing the surface roughness. These structures could be attributed to BHET dimer affecting the crystalline structure on the PET surface. The interruption of the crystalline order accompanied by the degradation of single polymer chains facilitated the crack propagation under mechanical stress, resulting in earlier failure of the incubated sample compared to the control. Within this study, we showed that biotic factors have a relevant impact on the pathway from macro- to microplastic, as material properties play a decisive role in the progress of plastic fragmentation. The investigations further hinted at certain preferences in substrate binding to PETase. Our results provide a first step towards understanding the impact of enzymatic treatment through the establishment of a reliable method for the quantification and development of a new experimental setup. The applied methods provide reliable data for the quantitative analysis of biotic impact by enzymatic degradation. 
The results gained from this pilot study provide the basis for future interdisciplinary research combining biochemistry and material science. Here, we established a method for the determination of enzymatic activity on material properties in a quantifiable fashion. This protocol can act as a foundation towards a full understanding of the interplay between enzyme and material. Future experiments must consider time-resolved analysis as well as a detailed characterization of the surface erosion and chemistry. Moreover, to fully cover the degradation process in nature with its implications on material properties, there is a need to include abiotic factors such as temperature, $\mathrm{pH}$, stage of weathering of PET material, and material composition with the parameters of biotic degradation like enzyme type or concentrations, incubation time, and buffer composition. The described method now provides a reliable platform to perform these studies in the future.

Author Contributions: Conceptualization, T.M., S.W. and B.H.; writing-original draft preparation, T.M. and S.W.; writing-review and editing, B.H., H.R. and V.A.; investigation, T.M., S.W., A.G., Y.E. and S.S.; supervision, B.H., H.R., V.A. and G.P. All authors have read and agreed to the published version of the manuscript.

Funding: This work was funded by the Deutsche Forschungsgemeinschaft (DFG, German Research Foundation)—project number 391977956-SFB 1357 Microplastics, subproject B01, C01, and C03.

Data Availability Statement: The data set used in this study is published on Zenodo, https: / / doi. org/10.5281/zenodo.5657200, accessed on 10 November 2021.

Acknowledgments: The authors would like to thank Sebastian Gröschel for sample preparation, Rika Schneider for GPC measurements, Alexander Brückner for dynamic-mechanical measurements, and Annika Pfaffenberger for SEM micrographs. We further acknowledge financial support by the University of Bayreuth Open Access Publishing Fund.

Conflicts of Interest: The authors declare no conflict of interest.

\section{References}

1. Thompson, R.C.; Olsen, Y.; Mitchell, R.P.; Davis, A.; Rowland, S.J.; John, A.W.G.; McGonigle, D.; Russell, A.E. Lost at Sea: Where Is All the Plastic? Science 2004, 304, 838. [CrossRef]

2. Weinstein, J.E.; Crocker, B.K.; Gray, A.D. From macroplastic to microplastic: Degradation of high-density polyethylene, polypropylene, and polystyrene in a salt marsh habitat. Environ. Toxicol. Chem. 2016, 35, 1632-1640. [CrossRef]

3. Waldman, W.R.; Rillig, M.C. Microplastic Research Should Embrace the Complexity of Secondary Particles. Environ. Sci. Technol. 2020, 54, 7751-7753. [CrossRef] [PubMed]

4. Khoironi, A.; Hadiyanto, H.; Anggoro, S.; Sudarno, S. Evaluation of polypropylene plastic degradation and microplastic identification in sediments at Tambak Lorok coastal area, Semarang, Indonesia. Mar. Pollut. Bull. 2020, 151, 110868. [CrossRef] [PubMed]

5. Zhang, K.; Hamidian, A.H.; Tubić, A.; Zhang, Y.; Fang, J.K.; Wu, C.; Lam, P.K. Understanding plastic degradation and microplastic formation in the environment: A review. Environ. Pollut. 2021, 274, 116554. [CrossRef] [PubMed]

6. Chamas, A.; Moon, H.; Zheng, J.; Qiu, Y.; Tabassum, T.; Jang, J.H.; Abu-Omar, M.M.; Scott, S.L.; Suh, S. Degradation Rates of Plastics in the Environment. ACS Sustain. Chem. Eng. 2020, 8, 3494-3511. [CrossRef]

7. Julienne, F.; Delorme, N.; Lagarde, F. From macroplastics to microplastics: Role of water in the fragmentation of polyethylene. Chemosphere 2019, 236, 124409. [CrossRef]

8. Kalogerakis, N.; Karkanorachaki, K.; Kalogerakis, G.C.; Triantafyllidi, E.I.; Gotsis, A.D.; Partsinevelos, P.; Fava, F. Microplastics Generation: Onset of Fragmentation of Polyethylene Films in Marine Environment Mesocosms. Front. Mar. Sci. $2017,4,84$. [CrossRef]

9. Gewert, B.; Plassmann, M.M.; MacLeod, M. Pathways for degradation of plastic polymers floating in the marine environment. Environ. Sci. Process. Impacts 2015, 17, 1513-1521. [CrossRef] [PubMed]

10. Kawai, F.; Kawabata, T.; Oda, M. Current knowledge on enzymatic PET degradation and its possible application to waste stream management and other fields. Appl. Microbiol. Biotechnol. 2019, 103, 4253-4268. [CrossRef] [PubMed]

11. Müller, R.-J.; Schrader, H.; Profe, J.; Dresler, K.; Deckwer, W.-D. Enzymatic Degradation of Poly(ethylene terephthalate): Rapid Hydrolyse using a Hydrolase fromT. fusca. Macromol. Rapid Commun. 2005, 26, 1400-1405. [CrossRef]

12. Sulaiman, S.; Yamato, S.; Kanaya, E.; Kim, J.-J.; Koga, Y.; Takano, K.; Kanaya, S. Isolation of a Novel Cutinase Homolog with Polyethylene Terephthalate-Degrading Activity from Leaf-Branch Compost by Using a Metagenomic Approach. Appl. Environ. Microbiol. 2012, 78, 1556-1562. [CrossRef]

13. Yoshida, S.; Hiraga, K.; Takehana, T.; Taniguchi, I.; Yamaji, H.; Maeda, Y.; Toyohara, K.; Miyamoto, K.; Kimura, Y.; Oda, K. A bacterium that degrades and assimilates poly(ethylene terephthalate). Science 2016, 351, 1196-1199. [CrossRef] [PubMed] 
14. Danso, D.; Schmeisser, C.; Chow, J.; Zimmermann, W.; Wei, R.; Leggewie, C.; Li, X.; Hazen, T.; Streit, W.R. New Insights into the Function and Global Distribution of Polyethylene Terephthalate (PET)-Degrading Bacteria and Enzymes in Marine and Terrestrial Metagenomes. Appl. Environ. Microbiol. 2018, 84, e02773-17. [CrossRef]

15. Fechine, G.; Souto-Maior, R.M.; Rabello, M.S. Structural changes during photodegradation of poly(ethylene terephthalate). J. Mater. Sci. 2002, 37, 4979-4984. [CrossRef]

16. Fechine, G.; Rabello, M.; Maior, R.S.; Catalani, L. Surface characterization of photodegraded poly(ethylene terephthalate). The effect of ultraviolet absorbers. Polymer 2004, 45, 2303-2308. [CrossRef]

17. Ioakeimidis, C.; Fotopoulou, K.N.; Karapanagioti, H.K.; Geraga, M.; Zeri, C.; Papathanassiou, E.; Galgani, F.; Papatheodorou, G. The degradation potential of PET bottles in the marine environment: An ATR-FTIR based approach. Sci. Rep. 2016, 6, 23501. [CrossRef] [PubMed]

18. Meides, N.; Menzel, T.; Poetzschner, B.; Löder, M.G.J.; Mansfeld, U.; Strohriegl, P.; Altstaedt, V.; Senker, J. Reconstructing the Environmental Degradation of Polystyrene by Accelerated Weathering. Environ. Sci. Technol. 2021, 55, 7930-7938. [CrossRef] [PubMed]

19. Allen, N.S.; Edge, M.; Mohammadian, M.; Jones, K. Hydrolytic degradation of poly(ethylene terephthalate): Importance of chain scission versus crystallinity. Eur. Polym. J. 1991, 27, 1373-1378. [CrossRef]

20. Edge, M.; Hayes, M.; Mohammadian, M.; Allen, N.; Jewitt, T.; Brems, K.; Jones, K. Aspects of poly(ethylene terephthalate) degradation for archival life and environmental degradation. Polym. Degrad. Stab. 1991, 32, 131-153. [CrossRef]

21. Sammon, C.; Yarwood, J.; Everall, N. An FT-IR study of the effect of hydrolytic degradation on the structure of thin PET films. Polym. Degrad. Stab. 2000, 67, 149-158. [CrossRef]

22. Arhant, M.; Le Gall, M.; Le Gac, P.-Y.; Davies, P. Impact of hydrolytic degradation on mechanical properties of PET-Towards an understanding of microplastics formation. Polym. Degrad. Stab. 2019, 161, 175-182. [CrossRef]

23. Fayolle, B.; Audouin, L.; Verdu, J. A critical molar mass separating the ductile and brittle regimes as revealed by thermal oxidation in polypropylene. Polymer 2004, 45, 4323-4330. [CrossRef]

24. Awaja, F.; Pavel, D. Recycling of PET. Eur. Polym. J. 2005, 41, 1453-1477. [CrossRef]

25. OECD. Improving Plastics Management: Trends, policy responses, and the role of international co-operation and trade. OECD Environ. Policy Pap. 2018, 12, 20. [CrossRef]

26. Austin, H.P.; Allen, M.D.; Donohoe, B.S.; Rorrer, N.; Kearns, F.; Silveira, R.L.; Pollard, B.C.; Dominick, G.; Duman, R.; El Omari, K.; et al. Characterization and engineering of a plastic-degrading aromatic polyesterase. Proc. Natl. Acad. Sci. USA 2018, 115, E4350-E4357. [CrossRef] [PubMed]

27. Altstädt, V. The Influence of Molecular Variables on Fatigue Resistance in Stress Cracking Environments. In Intrinsic Molecular Mobility and Toughness of Polymers II; Springer: Berlin/Heidelberg, Germany, 2005; pp. 105-152.

28. Liu, H.-Y.; Wang, G.; Mai, Y.-W. Cyclic fatigue crack propagation of nanoparticle modified epoxy. Compos. Sci. Technol. 2012, 72, 1530-1538. [CrossRef]

29. Runt, J.; Gallagher, K.P. The influence of microstructure on fatigue crack propagation in polyoxymethylene. J. Mater. Sci. 1991, 26, 792-798. [CrossRef]

30. Ramirez, A.; Manson, J.A.; Hertzberg, R.W. Fatigue crack propagation in amorphous poly(ethylene terephthalate). Polym. Eng. Sci. 1982, 22, 975-981. [CrossRef]

31. Altstaedt, V.; Keiter, S.; Renner, M.; Schlarb, A. Environmental Stress Cracking of Polymers Monitored by Fatigue Crack Growth Experiments. Macromol. Symp. 2004, 214, 31-46. [CrossRef]

32. Kothmann, M.; Zeiler, R.; de Anda, A.R.; Brückner, A.; Altstädt, V. Fatigue crack propagation behaviour of epoxy resins modified with silica-nanoparticles. Polymer 2015, 60, 157-163. [CrossRef]

33. Gibson, D.G.; Young, L.; Chuang, R.Y.; Venter, J.C.; Hutchison, C.A.; Smith, H.O. Enzymatic assembly of DNA molecules up to several hundred kilobases. Nat. Methods 2009, 6, 343-345. [CrossRef]

34. Wunderlich, B. Thermal Analysis of Polymeric Materials; Springer Science \& Business Media: Berlin/Heidelberg, Germany, 2005.

35. R Core Team. R: A Language and Environment for Statistical Computing; R Foundation for Statistical Computing: Vienna, Austria, 2021.

36. Kawai, F. The Current State of Research on PET Hydrolyzing Enzymes Available for Biorecycling. Catalysts 2021, 11, 206. [CrossRef]

37. Son, H.F.; Cho, I.J.; Joo, S.; Seo, H.; Sagong, H.-Y.; Choi, S.Y.; Lee, S.Y.; Kim, K.-J. Rational Protein Engineering of Thermo-Stable PETase from Ideonella sakaiensis for Highly Efficient PET Degradation. ACS Catalysts 2019, 9, 3519-3526. [CrossRef]

38. Groeninckx, G.; Reynaers, H. Morphology and melting behavior of semicrystalline poly(ethylene terephthalate). II. Annealed PET. J. Polym. Sci. Polym. Phys. Ed. 1980, 18, 1325-1341. [CrossRef]

39. Mancini, S.D.; Zanin, M. Recyclability of PET from virgin resin. Mater. Res. 1999, 2, 33-38. [CrossRef]

40. Güçlü, G.; Kasgöz, A.; Özbudak, S.; Özgümüs, S.; Orbay, M. Glycolysis of poly(ethylene terephthalate) wastes in xylene. J. Appl. Polym. Sci. 1998, 69, 2311-2319. [CrossRef]

41. Baliga, S.; Wong, W.T. Depolymerization of poly(ethylene terephthalate) recycled from post-consumer soft-drink bottles. J. Polym. Sci. Part A Polym. Chem. 1989, 27, 2071-2082. [CrossRef]

42. Krehula, L.K.; Hrnjak-Murgić, Z.; Jelenčić, J.; Andričić, B. Evaluation of Poly(ethylene-terephthalate) Products of Chemical Recycling by Differential Scanning Calorimetry. J. Polym. Environ. 2009, 17, 20-27. [CrossRef] 
43. Imran, M.; Kim, B.-K.; Han, M.; Cho, B.G.; Kim, D.H. Sub- and supercritical glycolysis of polyethylene terephthalate (PET) into the monomer bis(2-hydroxyethyl) terephthalate (BHET). Polym. Degrad. Stab. 2010, 95, 1686-1693. [CrossRef]

44. Fecker, T.; Galaz-Davison, P.; Engelberger, F.; Narui, Y.; Sotomayor, M.; Parra, L.P.; Ramírez-Sarmiento, C.A. Active Site Flexibility as a Hallmark for Efficient PET Degradation by I. sakaiensis PETase. Biophys. J. 2018, 114, 1302-1312. [CrossRef] [PubMed]

45. Tournier, V.; Topham, C.M.; Gilles, A.; David, B.; Folgoas, C.; Moya-Leclair, E.; Kamionka, E.; Desrousseaux, M.-L.; Texier, H.; Gavalda, S.; et al. An engineered PET depolymerase to break down and recycle plastic bottles. Nat. Cell Biol. 2020, 580, 216-219. [CrossRef]

46. Pecorini, T.; Hertzberg, R. The fracture toughness and fatigue crack propagation behaviour of annealed PET. Polymer 1993, 34, 5053-5062. [CrossRef]

47. Yeh, J.T.; Runt, J. Fatigue crack-propagation in annealed poly(butylene terephthalate). J. Mater. Sci. 1989, 24, 2637-2642. [CrossRef] 